\title{
El Manual del enfermero en los manicomios (1909) de Vicente Goyanes: preludio de la formación en enfermería psiquiátrica.
}

Vicente Goyanes “Manual del Enfermero en los Manicomios” (1909): prelude to training in psychiatric nursing.

\author{
Olga Villasante ${ }^{\text {a }}$ \\ ${ }^{a}$ Psiquiatra. Hospital Universitario Severo Ochoa. Madrid, España. \\ Correspondencia: Olga Villasante (ovillasante.hsvo@salud.madrid.org)
}

\section{Introducción}

La consolidación de la enfermería de salud mental como profesión autónoma y reconocida oficialmente es aún muy reciente, por ello es interesante bucear en los primeros intentos de formación, aún poco explorados, de los cuidadores psiquiátricos en España. Sin duda, el proceso estuvo relacionado con la institucionalización de la enfermería general que experimentó un gran avance durante las primeras décadas del siglo $\mathrm{XX}$, con la creación de la Escuela Nacional de Sanidad, el reconocimiento legal de los planes de estudio oficiales de practicantes y matronas o la apertura de las primeras escuelas de enfermería, entre otros hitos (1).

Si bien en Primeros intentos de profesionalización de la enfermería psiquiátrica: de la Segunda República a la posguerra española (2), ya habíamos analizado algunas de las iniciativas formativas surgidas en diferentes ámbitos geográficos españoles, el objetivo en esta sección es la reproducción del Manual del enfermero en los manicomios. La portada de este manual firmado en el Sanatorio de Conjo (sic) en abril de 1930 fue reproducida en el mencionado trabajo, sin embargo Couceiro Freijomil en el Diccionario bio-bibliográfico de escritores data el libro de Vicente Goyanes Cedrón (1865-1954) (3), en 1909 (4), por lo que emprendimos la búsqueda de este temprano ejemplar, tan escaso en los fondos bibliográficos (5). Consideramos de gran interés la reproducción de este Manual editado por la imprenta de José María Paredes en Santiago en 1909, cuando Goyanes ya era catedrático de Medicina y médico de Conxo.

La intención del médico gallego fue describir las condiciones que un enfermero, al cuidado de enfermos mentales, debía reunir y enumerar los deberes de estos cuidadores con los alienados. Merece la pena un breve análisis del contexto y el contenido de un manual ignorado muchas veces en la historia de la enfermería, como en la monografía de Francisco Ventosa Esquinaldo (6). darme las pistas sobre el Manual del Enfermero en los Manicomios y sus acertados comentarios sobre el texto. Sin duda, sin la colaboración de los dos compañeros gallegos este trabajo no hubiese sido posible.

Trabajo realizado en el marco de los Proyectos de Investigación HAR2012-37754-C02-01 (Ministerio de Ciencia e Innovación): Prácticas asistenciales y estrategias de institucionalización de la psiquiatría franquista (1939-1960). 
Vicente Goyanes Cedrón y el Manicomio de Conxo

Vicente Goyanes Cedrón, nacido en Ourense en 1865 y emparentado con los Barcia - una familia de médicos y psiquiatras que llega hasta nuestros días-, dedica el libro a su maestro Timoteo Sánchez Freire (18381912), primer director de la institución. Hay una segunda dedicatoria "a los enfermeros", en la que, además de una alabanza a su trabajo y a su noble misión, alude a la necesidad de formación de éstos para "hacerles llevar con relativa felicidad el desgraciado estado en que se encuentran". En la edición de 1930 del Manual, sin embargo, desaparece esta loable dedicatoria a los enfermeros y la primera página está dedicada al Arzobispo de Compostela, Fray Zacarías Martínez y, el ya entonces fallecido, Sánchez Freire pasa a la segunda página. No se puede desdeñar, tal como han señalado diversos autores (7), la poderosa influencia de la Iglesia en la institución gallega que, por una Real orden de 1891 (8), había aprobado que la Fundación Manicomio de Conxo fuera presidida por la Mitra compostelana (9)

En el momento de la publicación de la primera edición del libro de Goyanes, Sánchez Freire que había dirigido la institución desde 1885, ya había sido sustituido por Juan Barcia Caballero (1852-1926), director desde 1906. Vicente Goyanes, catedrático de Histología y Anatomía Patológica en Santiago y formado junto a Pío del Río Hortega o Pittaluga, había trabajado en el manicomio compostelano desde su apertura. La reedición del libro en 1930 coincidió con el breve período en el que Goyanes Cedrón dirigió la institución compostelana, en la que acababa de sustituir a Francisco Bacariza Varela. En este último, el texto se complementó con Atribuciones y deberes del personal facultativo en armonía con lo que dispone el Reglamento del Manicomio de Conjo (1930), aprobado por la Junta de Gobierno y Administración del Manicomio en mayo de
1931, que trataba de organizar la asistencia en la institución gallega, al estipular las funciones no sólo de los médicos, sino también de los practicantes. Entre ambas ediciones Goyanes también prologó Las carreras auxiliares médicas (1923) de Emilio Alonso García Sierra, en el que se dedicaban unas páginas al cuidado de los enfermos delirantes (10).

Si bien el libro de Goyanes es el primero que hemos localizado dirigido específicamente a enfermeros psiquiátricos se pueden rastrear otras publicaciones previas en las que se ocupaban del cuidado de enfermos mentales como el Prontuario del enfermero de José Rodrigo (11). El fin de este último manual publicado por primera vez en 1891, y reeditado en 1932 por el director facultativo de los manicomios de Ciempozuelos, era enseñar a los Hermanos Novicios ligeras nociones de fisiología, anatomía, cirugía, así como "los mejores métodos para cuidar como enfermeros a la diversa clase de enfermos en que han de emplear sus caritativos auxilios", tal como reza el preámbulo. Además, en el capitulo tres dedicado a los manicomios, incluye unas páginas para establecer unas reglas prácticas para los "enfermeros", y describe las actitudes para tratar a agitados, sucios, encamados, ayunadores o desfilachadores. A diferencia del de Goyanes, no es un libro específico de cuidados psiquiátricos y deviene de la necesidad de formar a los religiosos que contaban con escasa instrucción. Cronológicamente este prontuario de los Hermanos de San Juan de Dios estaba aún distante del proceso de cambio en el personal de las instituciones psiquiátricas y de la legislación que iba a permitir la obtención del diploma de enfermero.

Aunque Goyanes había estudiado Medicina en Santiago, sin duda, sus viajes a París, Berlín y Bruselas influyeron en la elaboración del Manual, ya que la formación de la enfermería en Europa había comenzado varias décadas antes. En 1885, la MédicoPsychologique Association había publicado el 
HISTORIAS CON HISTORIA

Handbook for the instruction of attendants on the insane que, en los años treinta, ya contaba con seis ediciones (12). Llama la atención, sin embargo, que en la edición de 1930, no se añada ningún contenido y no cite libros como $\mathrm{Der}$ seelisch kranke Mensch und seine Pflege [El enfermo mental y su cuidado], obra finlandesa publicada en 1926 y traducida al alemán por su propia autora, Neuman-Rahn, Hints to probationer Nurses in Mental Hospitals" editada en Londres, en 1926 o Geistekrankenpfleger [El cuidador de los enfermos mentales] que, en 1929, ya contaba con una tercera edición.

Las iniciativas formativas enfermeras van a partir, como en la mayor parte de los países, de los médicos que trabajaban en las instituciones psiquiátricas, quienes tampoco en España tenían reconocida oficialmente su especialidad. Estos alienistas, entonces en pleno proceso de legitimación de la psiquiatría, tal como recoge Rafael Huertas, en su conocido libro Organizar y persuadir. Estrategias profesionales y retóricas de legitimación de la medicina mental española (1875-1936) (13), pertenecieron a la llamada "Edad de Plata" y la Generación de Archivos de Neurobiología. Hay que destacar la iniciativa de Goyanes cuya práctica se hallaba centrada en una institución gallega bien alejada de Madrid o Barcelona, centros que clásicamente se han ligado a los avances de la "ciencia mental". De hecho, sobre estos dos núcleos pivotaron los cambios generados en el primer tercio de siglo, cuya su máxima expresión fue el Decreto sobre asistencia a enfermos mentales del 3 Julio de 1931 y la creación del Consejo Superior Psiquiátrico, que impulsó numerosas reformas ligadas a nombres como José Miguel Sacristán, Gonzalo Rodríguez Lafora o Enrique Fernández Sanz (14).

Los enfermeros psiquiátricos en el Manicomio de Conxo

El Manual del enfermero en los manicomios, se podría encuadrar en el proceso de transformación de la atención a los enfermos mentales que tuvo lugar durante las primeras décadas del siglo $\mathrm{XX}$, sin embargo estaba aún lejos de los cambios planteados en la reforma psiquiátrica republicana. Separado casi un cuarto de siglo del emblemático manual de Luis Valenciano La asistencia al enfermo mental, publicado en 1933, dista de su riqueza y soporte bibliográfico (15). El libro del neuropsiquiatra murciano, subdirector del Sanatorio Neuropático de Carabanchel Bajo, cita manuales en lengua inglesa, alemana, francesa o finlandesa, ausentes en el libro del gallego.

En la introducción y antes de abordar las "condiciones que debe reunir el enfermero" el facultativo gallego alude a la necesidad de la vulgarización de los principios de la perturbación mental y remarca que éstos deben ser conocidos por los cuidadores. No se olvida Goyanes del clásico guiño al "mito fundacional" de los manicomios en España. Parafraseando a un alienista a quien no cita, el médico de Conxo enumera las condiciones del enfermero que incluyen "moral y prudente, cariñoso y buen observador, sobrio y arreglado, inclinado a cumplir con su deber, amigo del orden y del aseo, y que tenga iniciativas" (Goyanes, p.8). Estas cualidades asimiladas a las de un ángel de la guarda están, además, cargadas de un sentido religioso propio del cuidado de los enfermos hasta entonces.

Los problemas con el personal subalterno fueron identificados en esas décadas y la Sociedad de Neurología y Psiquiatría, fundada en 1911, consideró la organización de un cuerpo de enfermeros/as en los asilos. En el conocido artículo Gonzalo Rodríguez Lafora La polémica en torno a los manicomios de 1916, objeto de otra aportación de "historias con historia" en el número de 112 de esta Revista (16), se señalaba a los vigilantes del Manicomio de Valencia como "hombres ineducados, sucios desgarbados"(17), destacando la escasa profesionalización de la enfermería. No fue hasta la Segunda República, cuando 
la formación de enfermeros y enfermeras comienza a adquirir un carácter lacio-profesional y se descarga del sentido caritativoreligioso previo (18).

La reglamentación de las funciones del personal "enfermero" no mejoró la situación en el Manicomio de Conxo, a juzgar por el informe de Bacariza, el director al que sucedió Goyanes, quien señalaba, en 1927, la escasez de empleados y los bajos sueldos, circunstancias que no favorecían una buena atención al enfermo. La reedición del Manual del enfermero en los manicomios, en 1930, coincide con una tentativa de avance asistencial cuando además trabajaban en la institución el ex director Bacariza Varela, Pérez López Villamil y Lois Asorey. Sin embargo, la situación aún empeoró en los siguientes años y pudo precipitar la dimisión de Goyanes en 1931. Sólo tres años después, cuando Ramón Rodríguez Somoza ocupaba la dirección una denuncia de los empleados criticaba despidos de personal subalterno y condiciones precarias de las enfermeras (19).

El médico de Conxo, después de describir brevemente las condiciones del enfermero enumera las diferentes tipologías de "locos": agitados, tranquilos -entre los que incluye los tristes-, epilépticos, sucios o cliniquesas y recluidos judicialmente. Estos grupos eran, en general, separados en departamentos que recibían estos mismos nombres -sección de tranquilos, de agitados, de sucios...- y se han mantenido hasta bien entrado el siglo XX, en la mayor parte de las instituciones psiquiátricas españolas. Entre estos grupos advierte especialmente de la agresividad de los epilépticos y describe el modo de actuar para prevenir el daño en los accesos epilépticos. En el siguiente apartado del libro de Goyanes se expone "la conducta que los enfermeros deben observar con los enfermos", a quienes asimila a niños susceptibles de enseñarles reglas de urbanidad, orden, limpieza y prácticas religiosas. Este conjunto de actuaciones que el enfermero debía atender eran premisas del tratamiento moral y físico de los alienados y las expone organizadas en las siguientes áreas: limpieza, alimentación, vestido, sueño y medios de sujeción. Si bien la literatura médica de esa época había asimilado teóricamente el non-restraint, las denuncias de la prensa, como el ya citado artículo de Rodríguez Lafora pocos años después, reflejaban instituciones españolas deplorables con enfermos con grilletes y cadenas. Goyanes argumenta que los métodos restrictivos podían evitarse con el talento del enfermero y la confianza de éste con el enfermo, de modo que la sujeción debía reducirse a lo mínimo y emplearse sólo con una orden médica.

En las últimas páginas del Manual, el médico gallego enumera 15 deberes que los distribuye en otros tantos artículos, relacionados con las disposiciones del Reglamento por el que se regía la institución compostelana. En realidad resume el contenido del Manual y su lectura nos ilustra sobre los cuidados básicos que, si bien un siglo más tarde parecen obvios para una enfermería psiquiátrica especializa$\mathrm{da}$, era preciso reglamentar en instituciones cuyo personal en esa época, incluido el facultativo, carecía de una formación básica y elemental sobre las enfermedades mentales.

\section{Los manuales de enfermería durante la Se- gunda República}

El breve Manual del enfermero en los manicomios no es sino el preámbulo de una serie de publicaciones que trataron de sistematizar los conocimientos necesarios para el cuidado de los enfermos mentales. Décadas después, durante la Segunda República (19311936) se produjeron numerosos cambios legislativos que permitieron una mejor formación para enfermeros y enfermeras (20), entre las que destaca la regulación del Diploma de enfermero psiquiátrico, cuyos requisitos fueron recogidos en la orden del 16 de mayo de 
1932 (21). En general, los textos de los años treinta trataron de dar respuesta al programa oficial para obtener el certificado de aptitud de "enfermero psiquiátrico", que comprendía 24 lecciones.

El primero del que tenemos constancia, El enfermero psiquiátrico, fue publicado en Elda por el director del Sanatorio Mental López Mora, en 1932 (22). En julio de ese mismo año el Consejo Superior Psiquiátrico convocó un concurso para la presentación de una obra que se ajustara al programa de formación. La asistencia al enfermo mental de Luis Valenciano resultó premiado y, editado en 1933, fue recomendado, aunque algunas instituciones buscaron más alternativas a las carencias formativas del personal, en ocasiones diferentes en función del género del cuidador (23). Por ejemplo, el subdirector del Sanatorio de Ciempozuelos para hombres, Eulogio García de la Piñera escribió Lecciones teóricas y prácticas para contestar al curso elemental de enfermeros psiquiátricos en 1935 (24), mientras que José Salas, el médico del manicomio de Mujeres de Ciempozuelos publicó, en 1935, Manual de la enfermera general y psiquiátrica, cuyo fin principal era la instrucción de las cuidadoras de enfermas mentales (25). En general, estos libros recogieron las lecciones y cursos organizados en las diferentes instituciones como en la Clínica Mental de la Diputación de Barcelona, donde Ricardo Bordás Jané recopiló las Contestaciones al programa oficial para obtener el diploma de enfermero psiquiátrico (26), o en el Manicomio de Valencia, donde el Prontuario del enfermero psiquiátrico, sintetizó las lecciones impartidas por su director Francisco Domingo Simó (27).

En resumen, se podría afirmar que el Manual de Goyanes es destacable por ser el primero de esta serie de interesantes libros, aun por investigar. Su difusión fue prácticamente nula en la península e incluso escasa dentro del ámbito gallego. Traduce la sensi- bilidad e inquietud del director de Conxo y su reproducción interesa en la medida que es un texto casi desconocido y prácticamente ignorado. Consideramos que fue el preludio de un intento de "organización" de la enfermería psiquiátrica en España, que fracasó por la falta de estructuras asociativas, publicaciones científicas específicas y acusaciones de intrusismo. La guerra civil, sin duda, interrumpió y fragmentó la formación y las condiciones para que un grupo de profesionales pudiera reivindicar la especialización.

\section{Bibliografía}

(1) Hernández Martín, F (eds.). Historia de la Enfermería en España. Madrid: Síntesis, 1996: 227- 240

(2) Villasante, O. Primeros intentos de profesionalización de la enfermería psiquiátrica: de la Segunda República a la Posguerra Española. En: Simón David et al. (eds) Razón, locura y sociedad. Una mirada a la historia desde el siglo XXI, Madrid, AEN, 2013: 315329.

(3) Simón Lorda, D. Locura, Medicina y Sociedad. 1875-1975, Xunta de Galicia, 2005: 215-7.

(4) Couceiro Freijomil, A. Diccionario biobibliográfico de escritores, Santiago, Editorial de los bibliófilos gallegos, 1952: 205-6.

(5) Goyanes Cedrón, V. Manual del enfermero en los manicomios. Santiago: Tipo de José Ma Paredes, 1909.

(6) Ventosa Esquinaldo F. Cuidados psiquiátricos de enfermería en España (siglos $\mathrm{XV}$ al XX). Una aproximación histórica. Madrid: Editorial Díaz de Santos, 2000.

(7) González Fernández, E. A psiquiatría en Galicia. A psiquiatria galega e Conxo, Do Rueiro, Madrid, 1977.

(8) Angosto Saura, T., García Álvarez, M., González García, A. Historia del Manicomio de Conxo: sus primeros médicos y sus clasificaciones diagnósticas (un estudio a través de 528 
historias clínicas). Siso-Saúde, 1998, 31, 17-30.

(9) Torres Cubeiro, M. Equivalentes funcionales: Catolicismo, Banca y Psiquiatría privada. La fundación Manicomio de Conxo en Santiago de Compostela (1885-1931), Fes, Navarra, 2010. disponible en: torrescubeiro. weebly.com/med-soc.html.

(10) Alonso García Sierra, E. Las Carreras Auxiliares Médicas, Madrid: Librería internacional de Romo, 1923: 290-2.

(11) Rodrigo J. Prontuario del enfermero. Madrid: Imprenta y librería de Nicolás Moya, 1891

(12) Handbbook for the instruction of attendants on the insane, consultado el 25 de abril de 2013 en http://archive.org/details/ handbookforinst01assogoog

(13) Huertas, R. Organizar y persuadir. Estrategias profesionales y retóricas de legitimación de la medicina mental española (1875-1936). Madrid: Frenia, 2002.

(14) Campos R. Huertas García-Alejo, R. Estado y asistencia en España durante el primer tercio del siglo XX, Rev Asoc esp Neuropsiq (Madr) 1998; 65(18):99-108.

(15) Valenciano, L. La asistencia al enfermo mental. Publicaciones de Archivos de Neurobiología, 1933

(16) Villasante, O. La Polémica en torno a los manicomios, 1916. Rev. Asoc. Esp. Neuropsiq., 2011, 31 (112): 767-89

(17) Rodríguez Lafora, G. Los manicomios españoles, España, 12 oct 1916, 90: 8-10.

(18) Siles Gonzáles, J. Origen histórico de la profesionalización de los cuidados mentales: los practicantes, enfermeros y visitadoras psiquiátricas. Enfermería Científica, $\mathrm{n}^{\circ}$ 174175, 1996: 49-53.

(19) Simón Lorda, D. La asistencia psiquiátrica en Galicia en las Segunda República (1931-1936). En Angosto Saura, T., Rodríguez López, A., Simón Lorda, D. Setenta y cinco años de historia de la psiquiatría 19241999, AEN- AGS, Ourense, 2001, p. 228.

(20) Vera Pérez, J. A. Hernández Conesa, J. M. Un análisis educativo de la formación enfermera en España durante la Segunda República, Murcia, Diego Marín Librero editor, 2011.

(21) Gaceta de Madrid, 20 mayo de 1932.

(22) López Mora, M., El enfermero psiquiátrico, Elda, 1933

(23) Miqueo, C., Muñoz Zaragoza, B. La Enfermería Psiquiátrica. En Fernández Doctor (coord.), Historia de la psiquiatría del siglo XX en Aragón, 2014: 337-369.

(24) García de la Piñera E. Lecciones teóricas y prácticas para contestar al curso elemental de enfermeros psiquiátricos. Ciempozuelos: Imprenta hermanos de San Juan de Dios, 1935.

(25) Salas, J. Manual de la enfermera general y psiquiátrica. Madrid: Hermanas Hospitalarias del Sagrado Corazón de Jesús, 1935.

(26) Bordás y Jané, R. Contestaciones al programa oficial para obtener el diploma de enfermero psiquiátrico, Barcelona, Librería aragonés, 1933.

(27) Doming Simó F. Prontuario del enfermero psiquiátrico. Valencia. Imp. V. Climent Vila, 1936. 


\section{MANUAL}

$\longleftarrow \mathrm{DEL} \rightleftharpoons$

\section{ENFERMERO EN LOS MANTCOMIOS}

$$
\longleftarrow \text { POREL }
$$

\section{DR. D. D. GOPANES CEDRÓR}

\section{CATED RÁTICO DE MEDIGINA Y MÉDICO DEL SANATORIO DE CONJO}

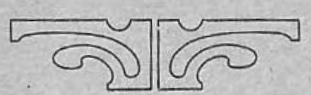

SANTIAGO: IMP, DE JOSE M. PAREDES

$$
1909
$$



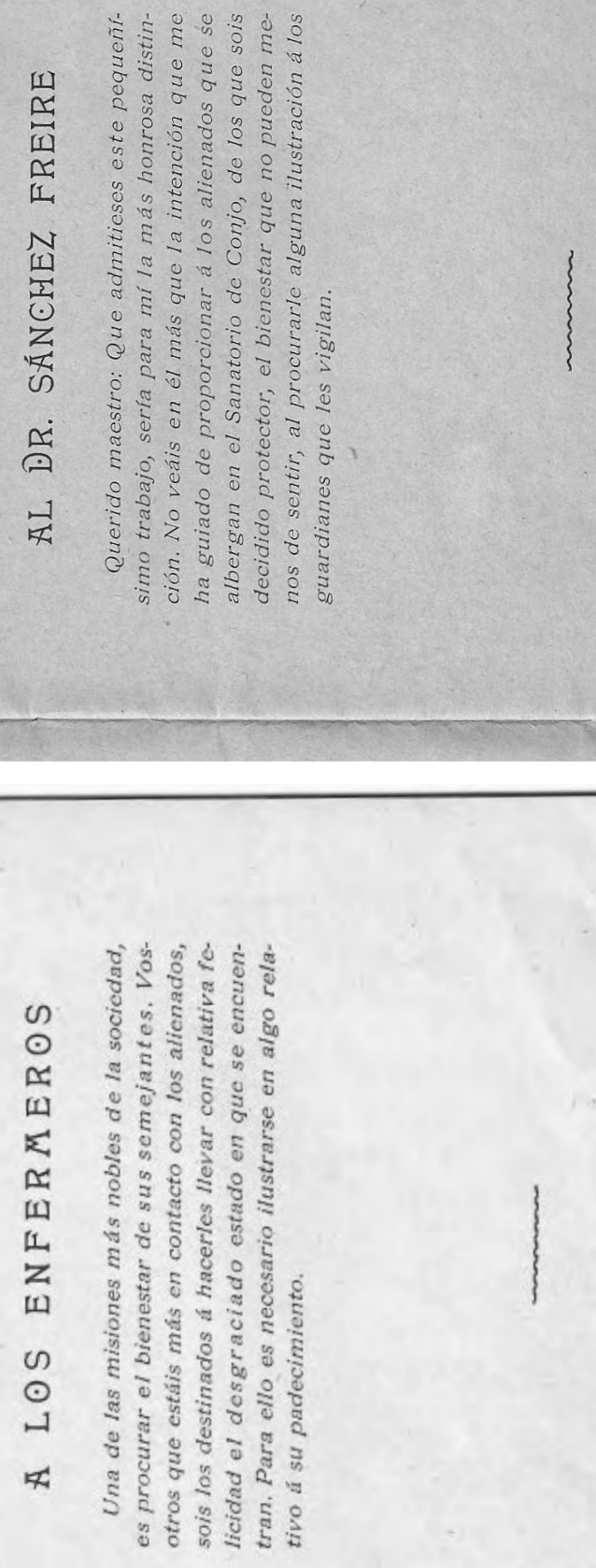


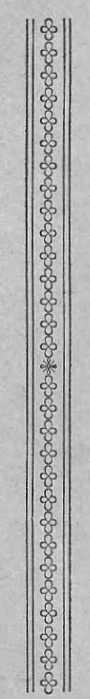

๖

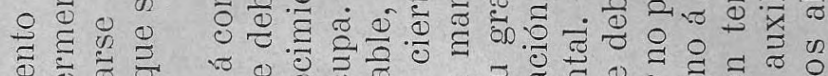

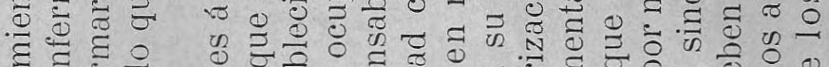

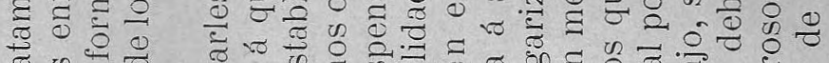

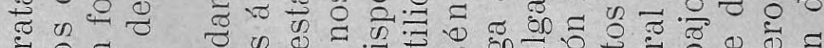

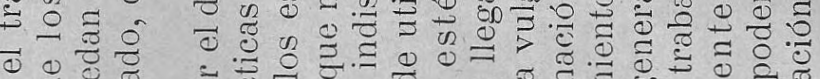
ब

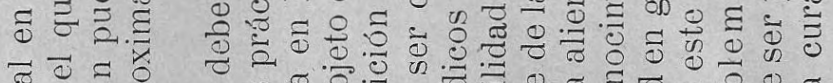

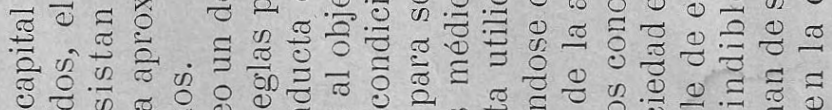

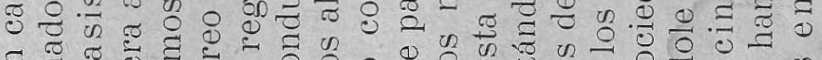

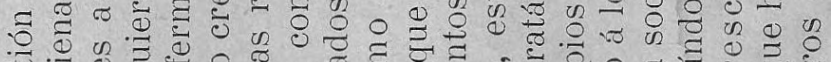

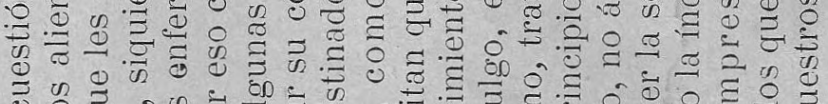

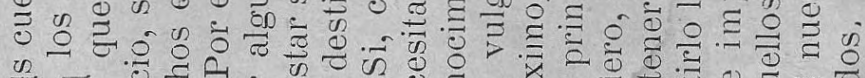

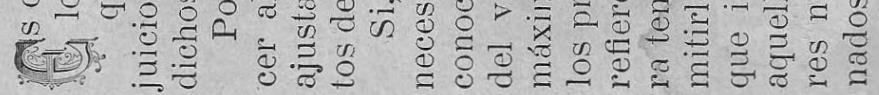




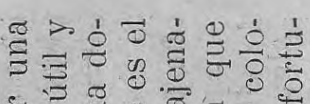
5.

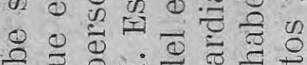
웡

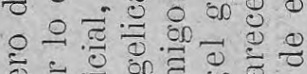

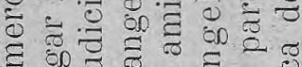

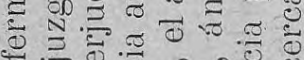

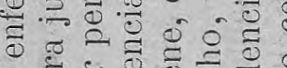

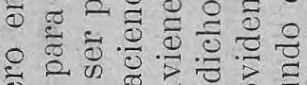

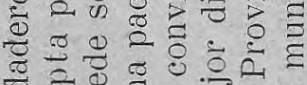

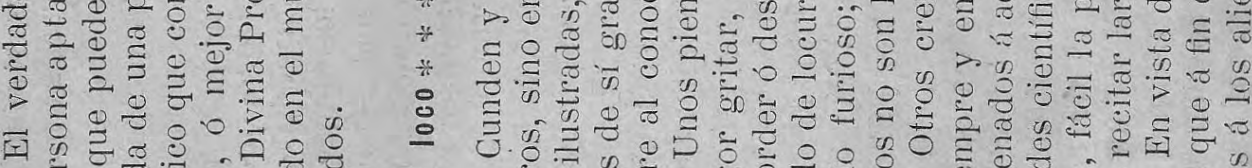

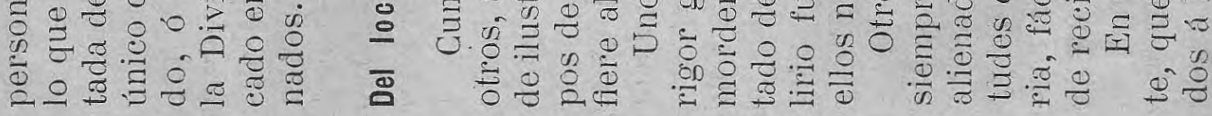

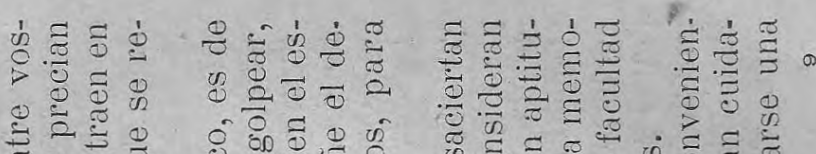

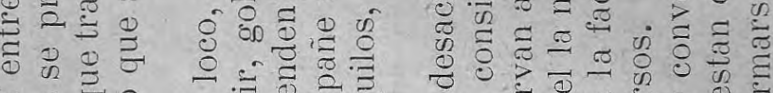

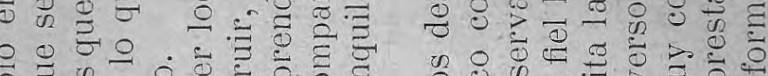

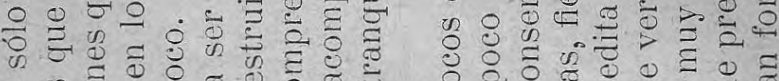
o g

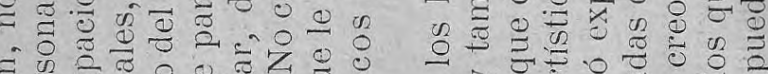

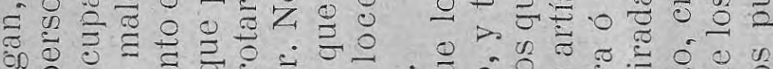

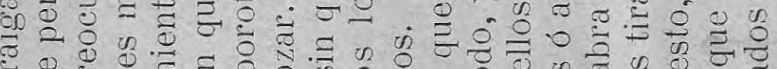

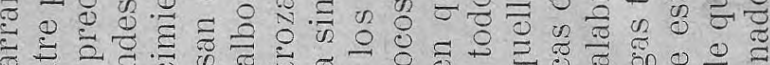
क人 의

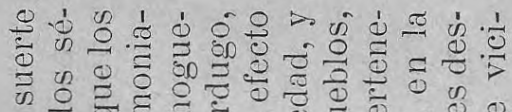

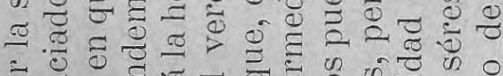
इ

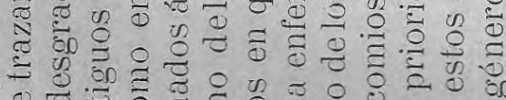

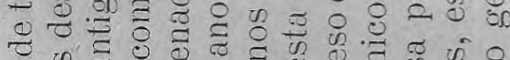
Q 0 \% थ

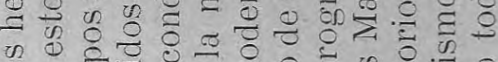

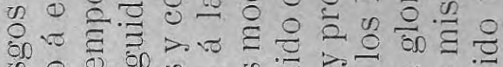

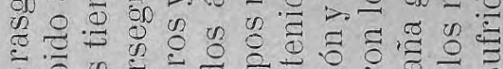

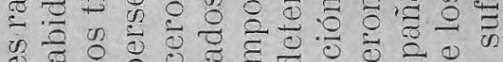
प)

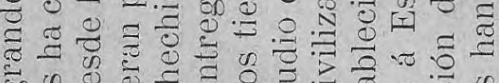

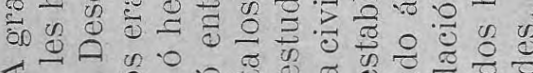

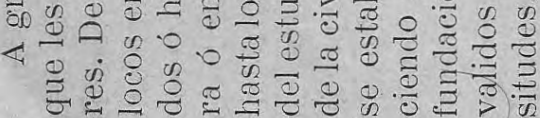

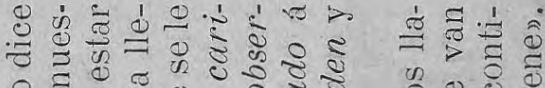

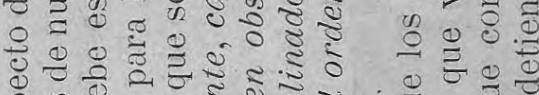

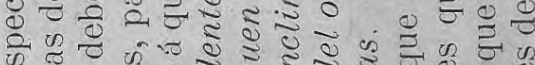

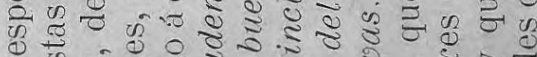

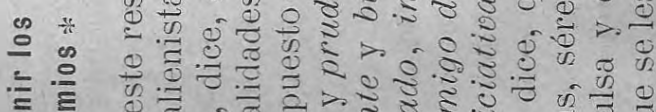

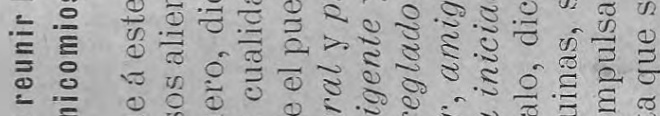
= ल छ ๑) 0 0 ए

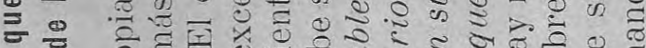
क क उ

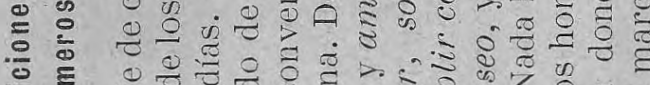
इएँ 


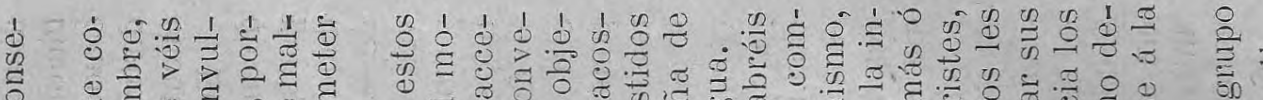

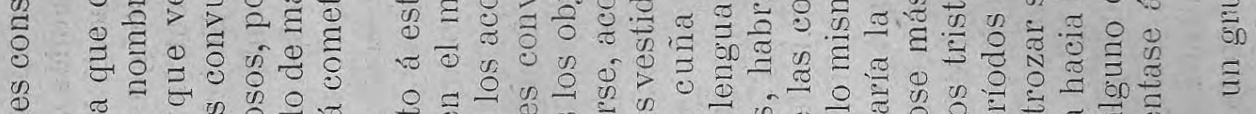

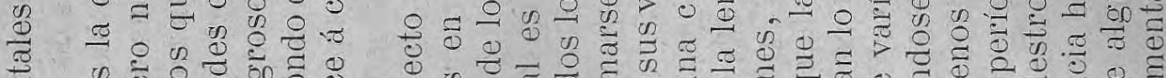

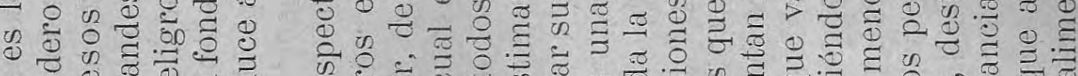

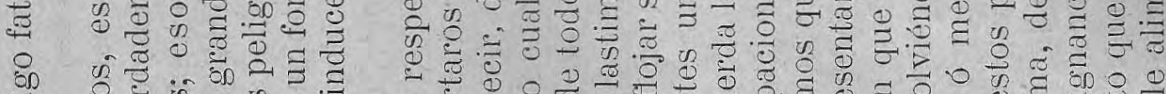

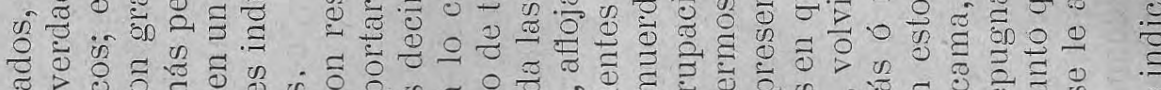

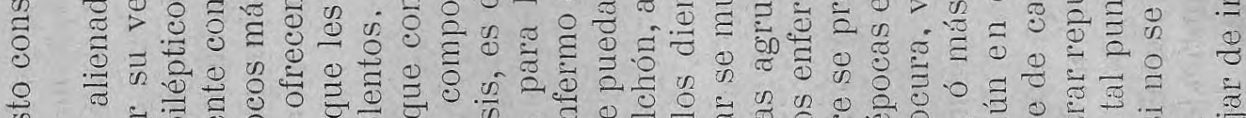

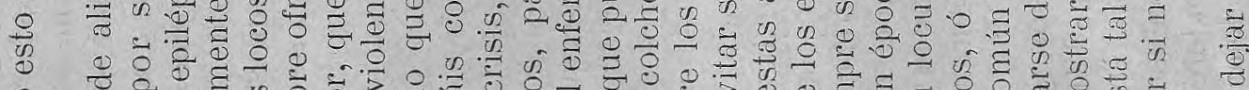

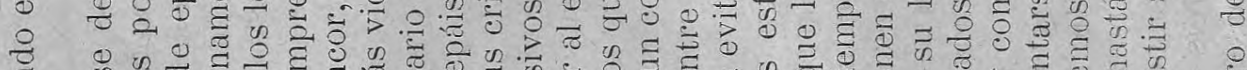

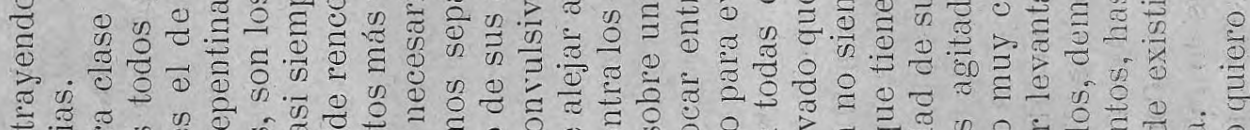

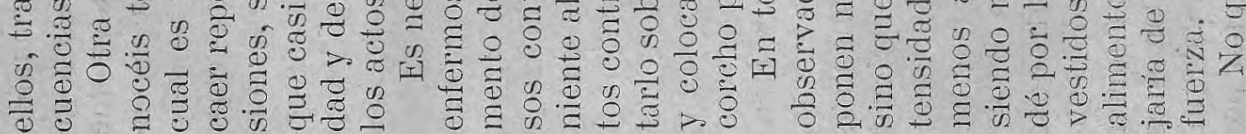

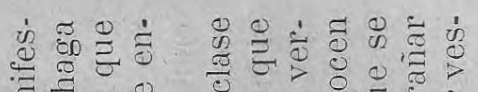

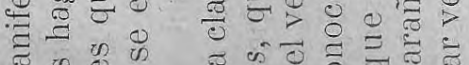

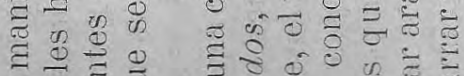

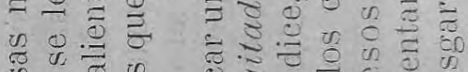

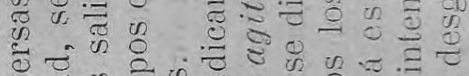

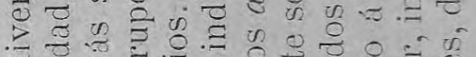

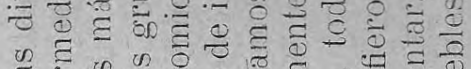
D)

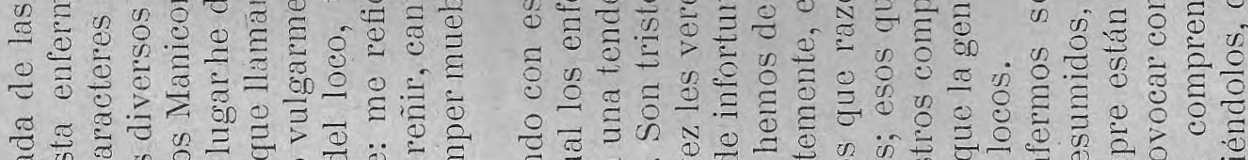

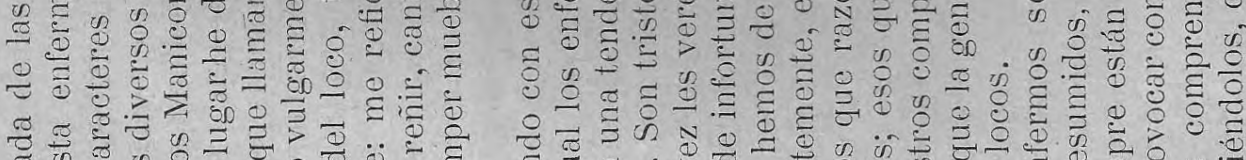

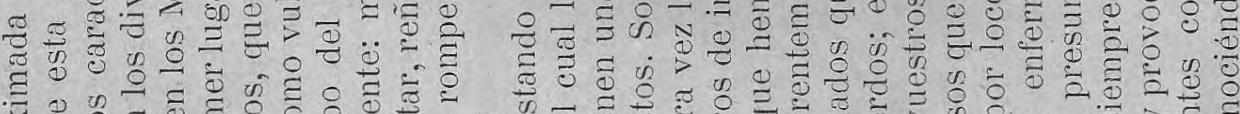

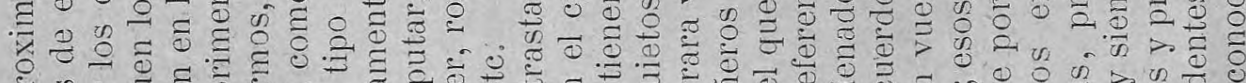

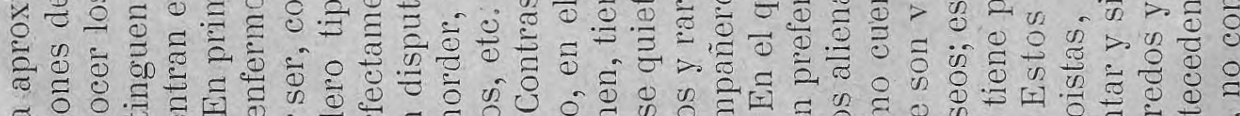

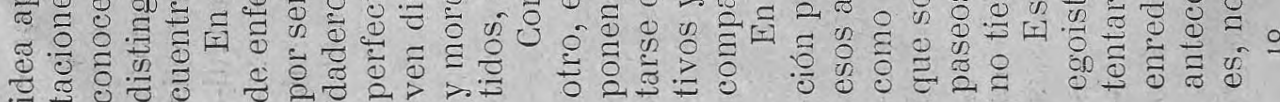

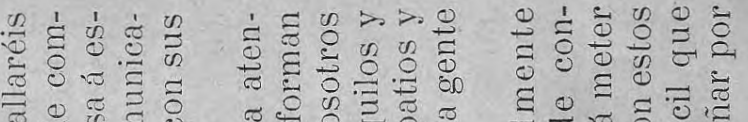

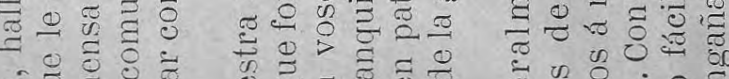

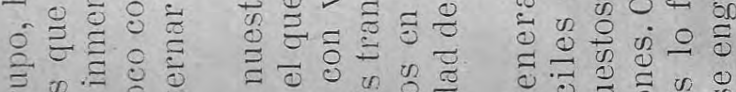

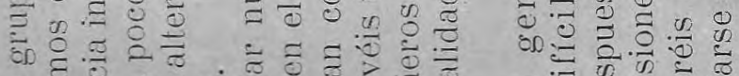

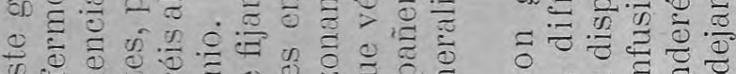
Uै

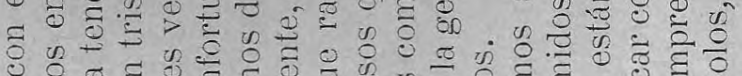




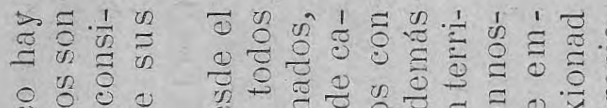

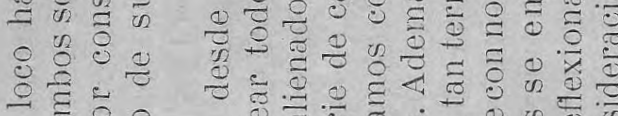

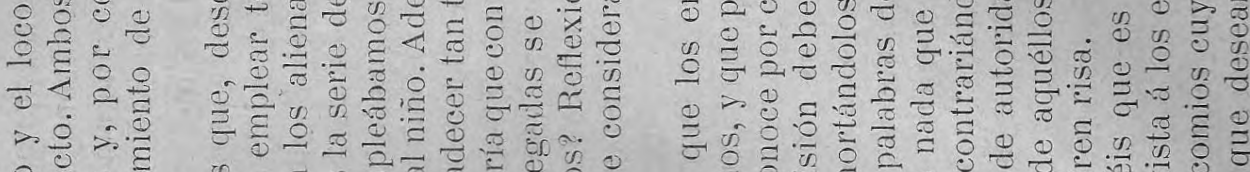

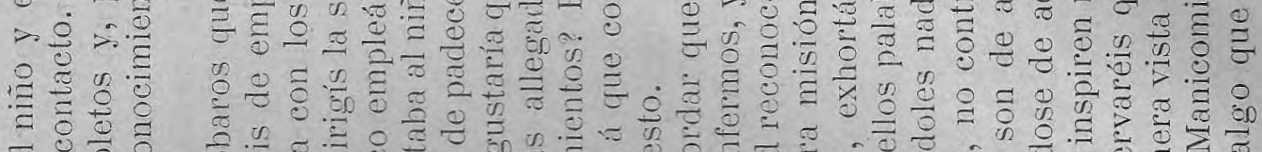

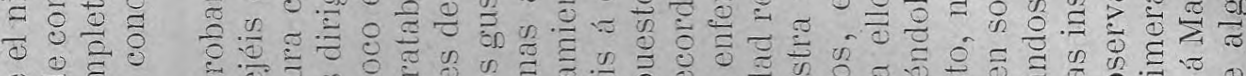

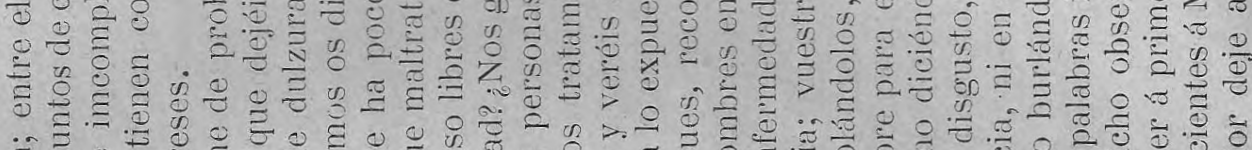

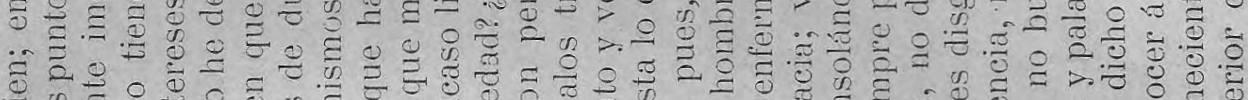

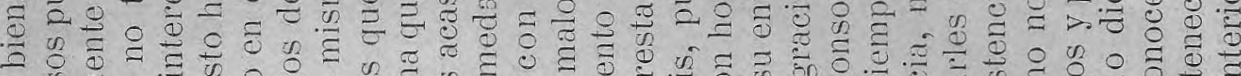

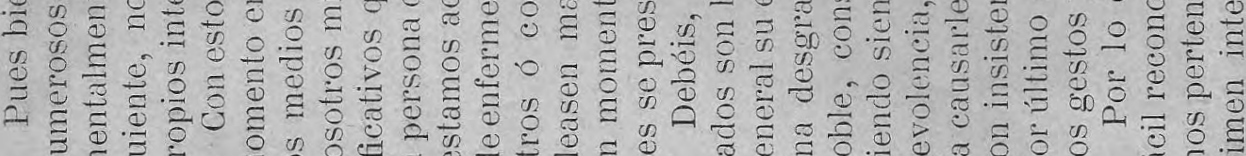

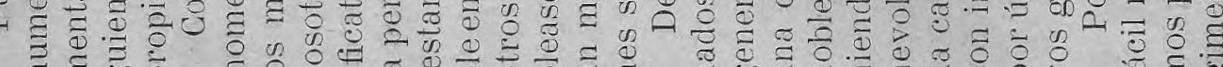

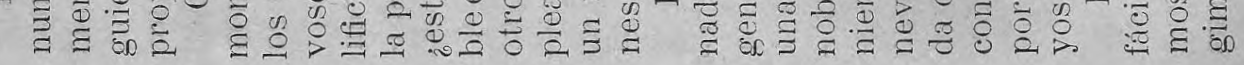

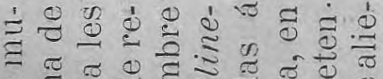

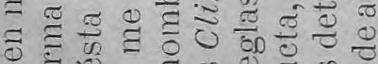

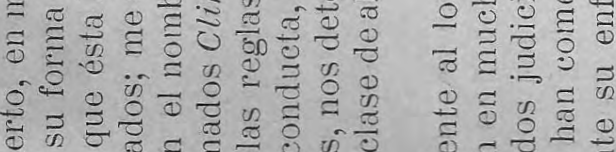

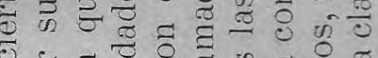
ए 2. 0 \% क के है

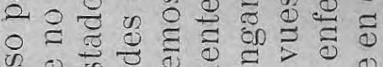

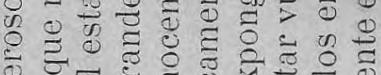

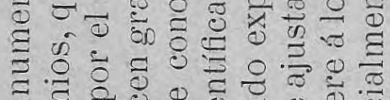
मे

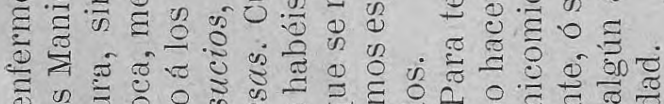

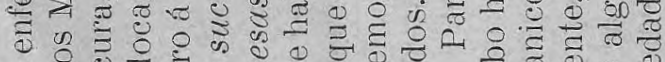

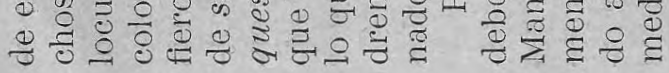

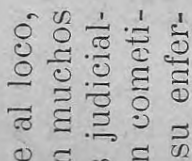

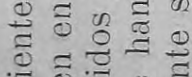

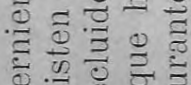

ङ.

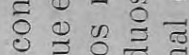

○

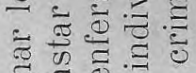

छ

ฮั 


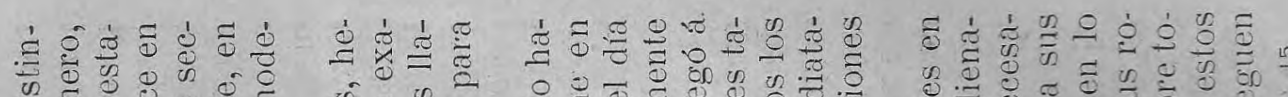

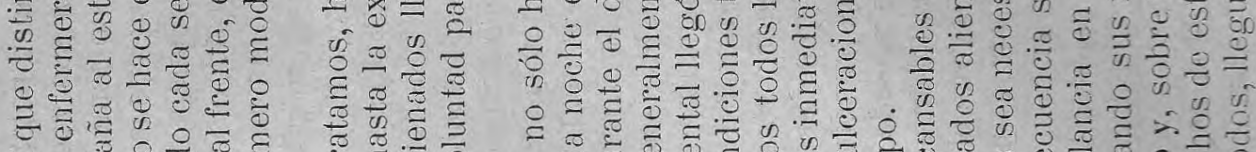

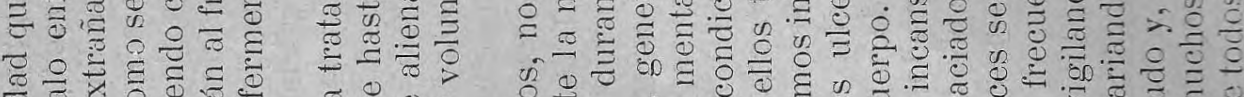
: 疋

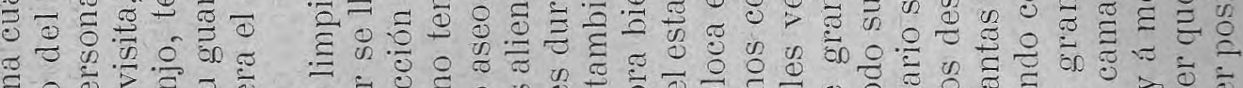

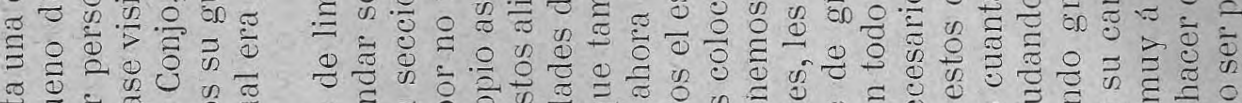

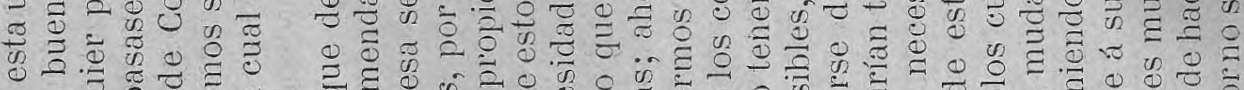

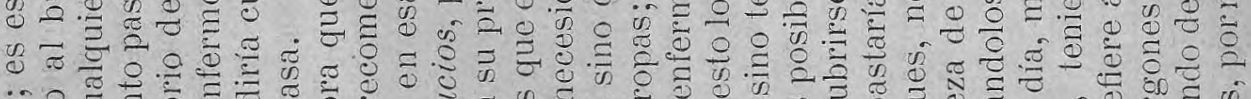

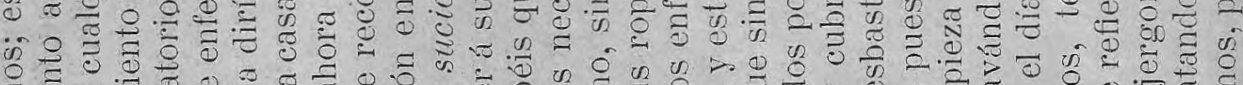

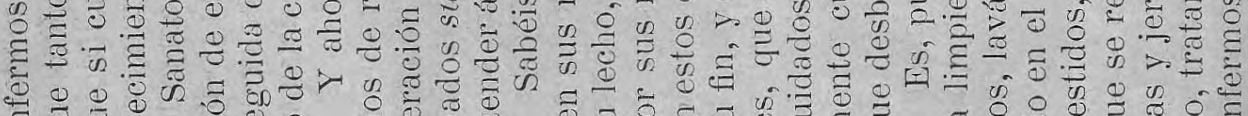

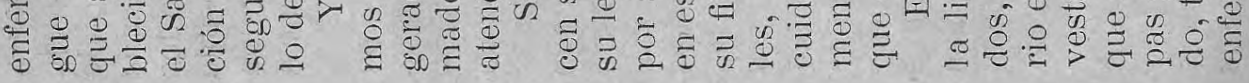

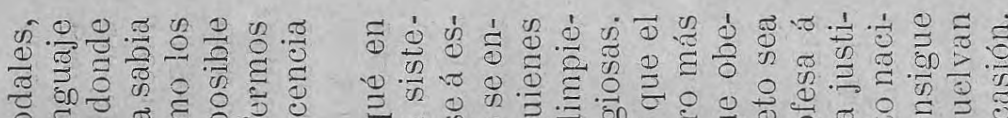

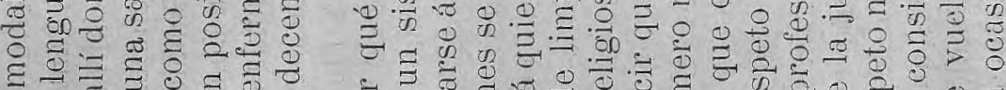

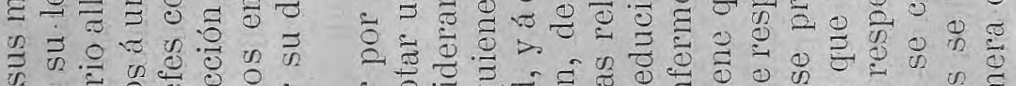

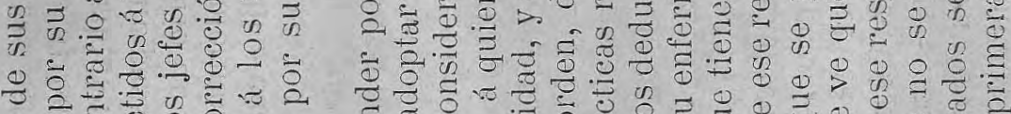

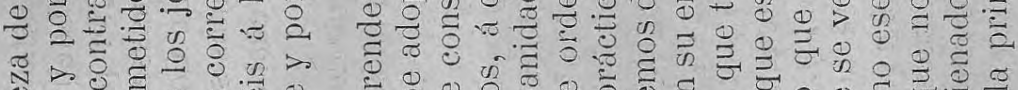

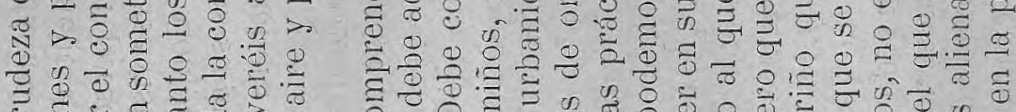

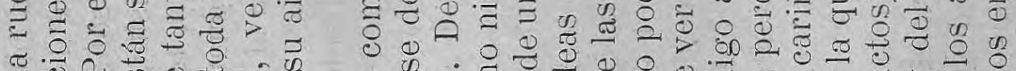

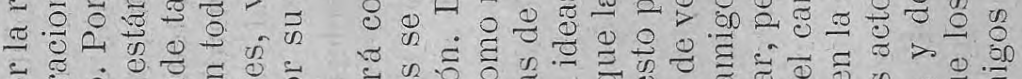

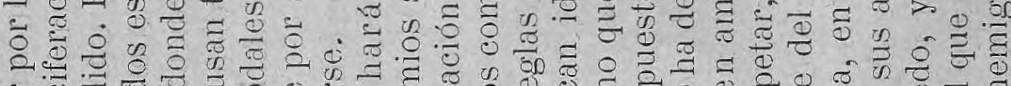

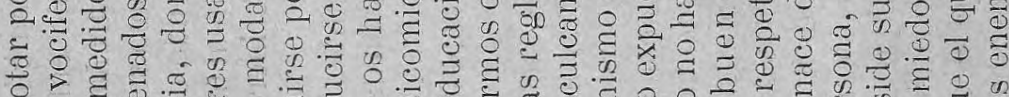

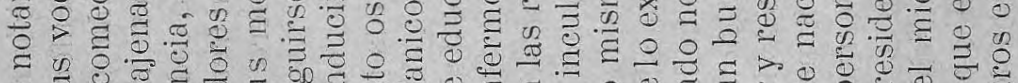

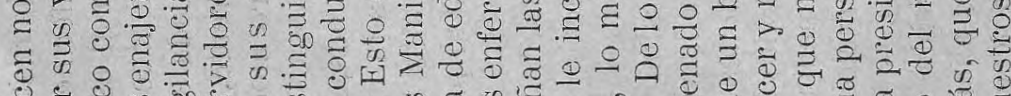

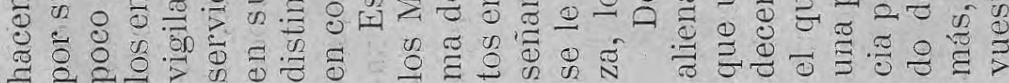

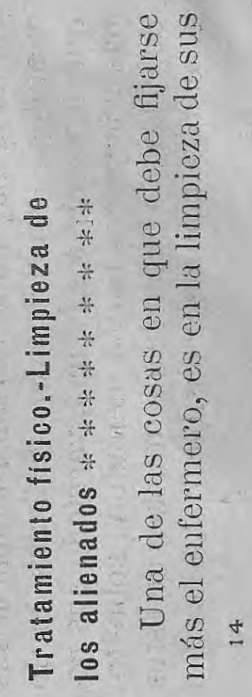




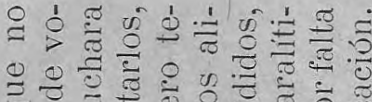
Е

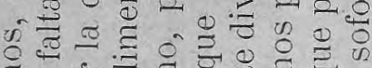
छ

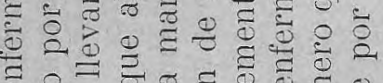

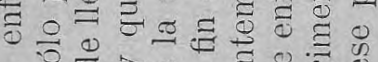
की

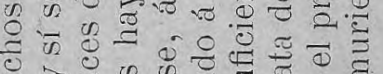

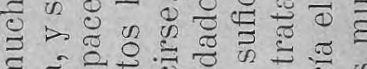

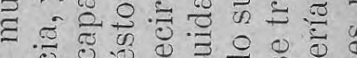

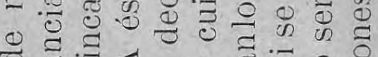

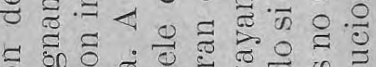

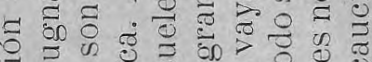

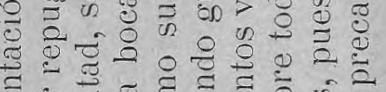

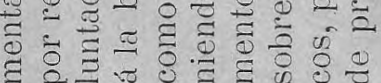

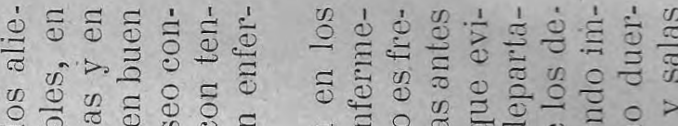

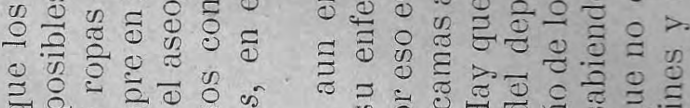

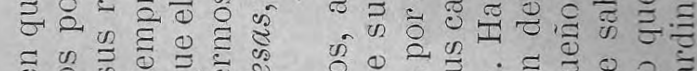

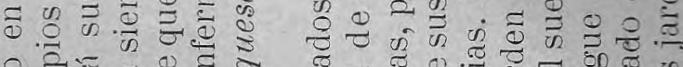

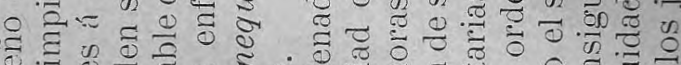

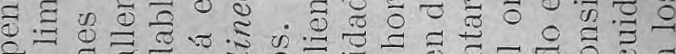

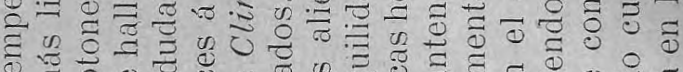
(1) छ

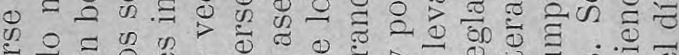

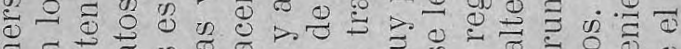

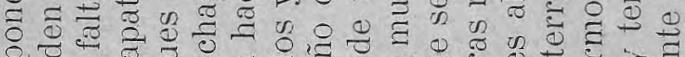
\%

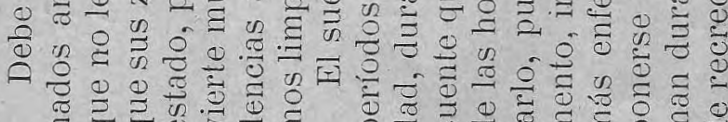

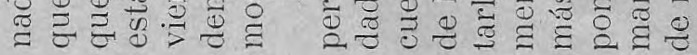

$\frac{9}{80}$

$\sqrt{2}$ की

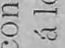

का है

过

$\therefore \frac{\pi}{\sigma}$

욜

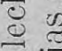

क

कै

可

궁

$=\dot{0}$

¿

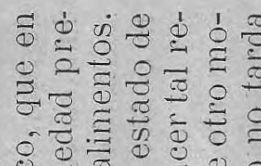

:

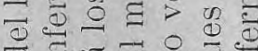

อ

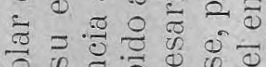

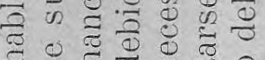

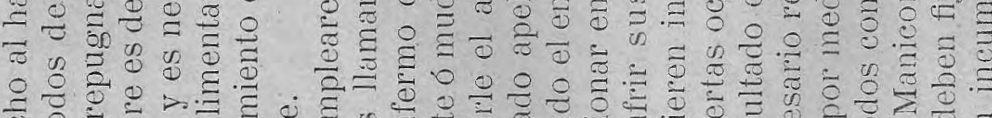

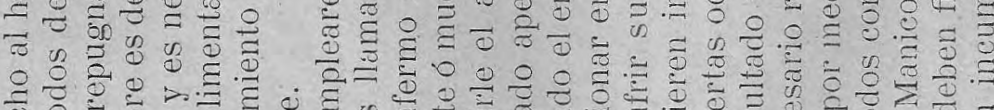

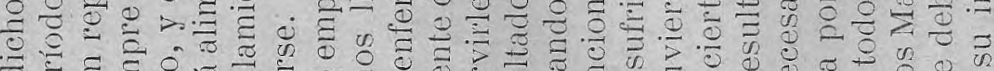

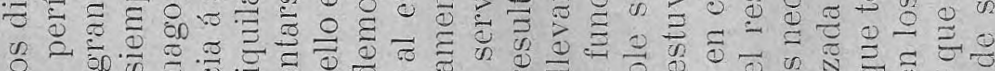

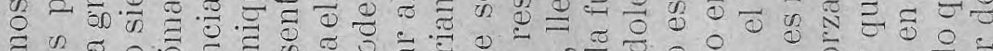
๙ $\stackrel{0}{0}$

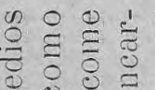

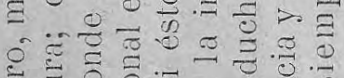

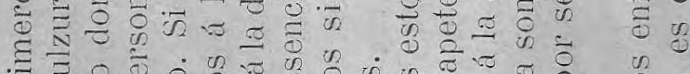

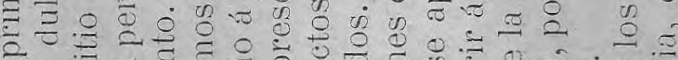

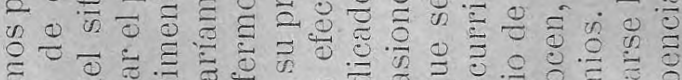
๘

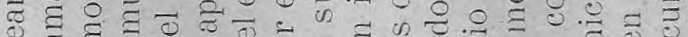
(1) 列 


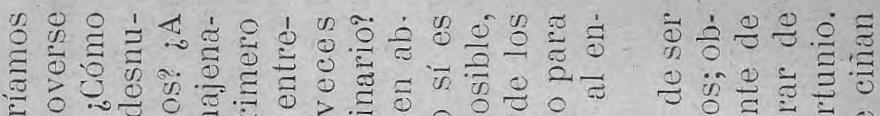

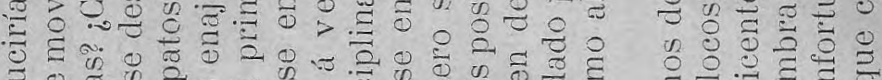

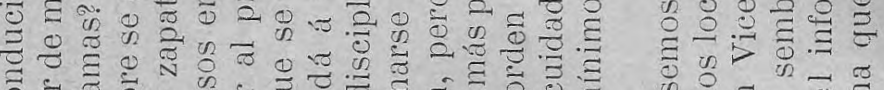
పี

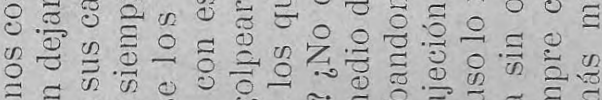

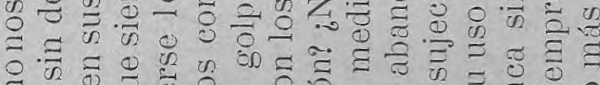

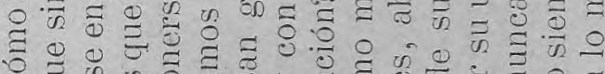

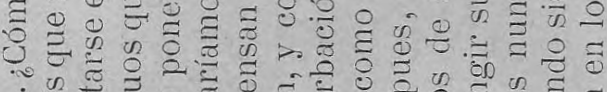

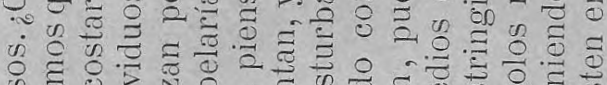

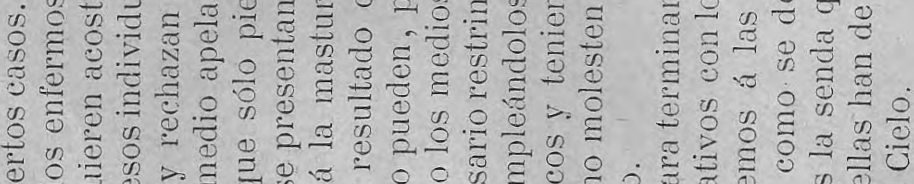

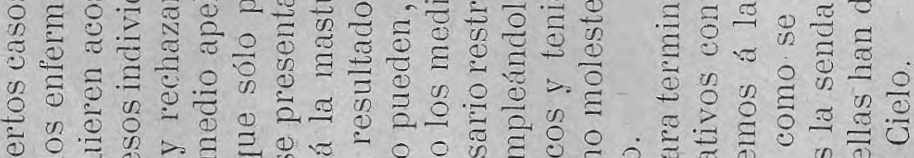

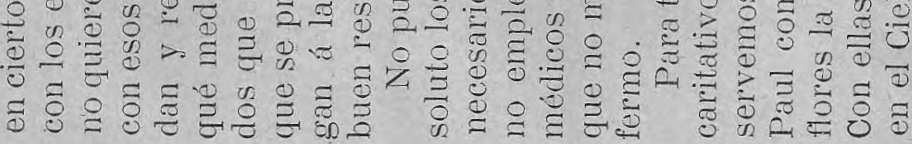

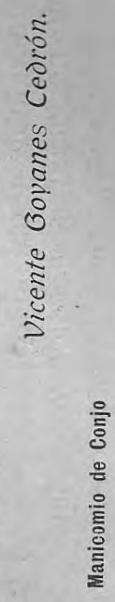

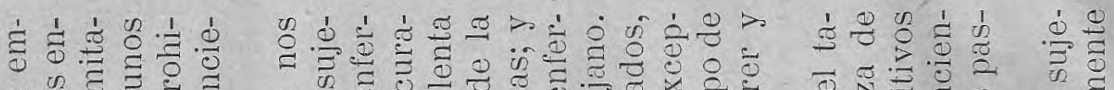

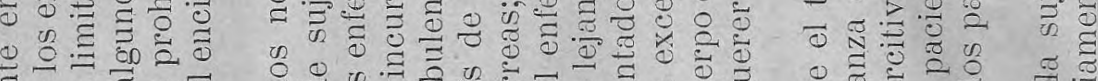

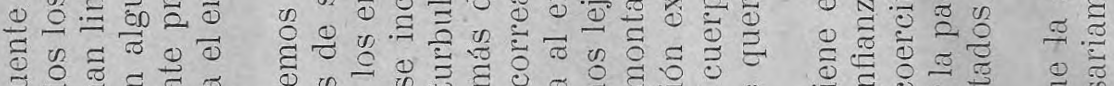

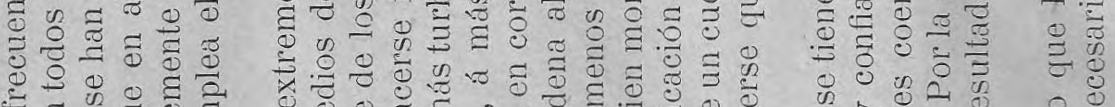

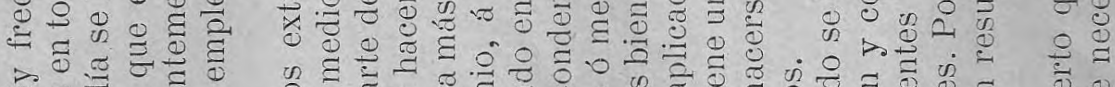

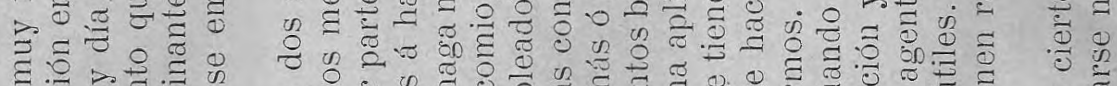

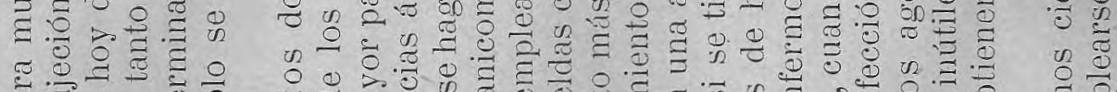

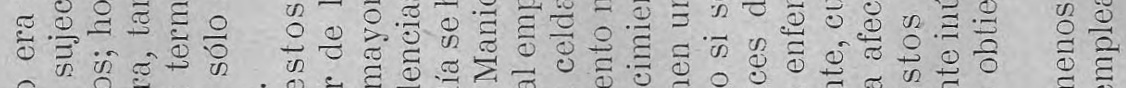

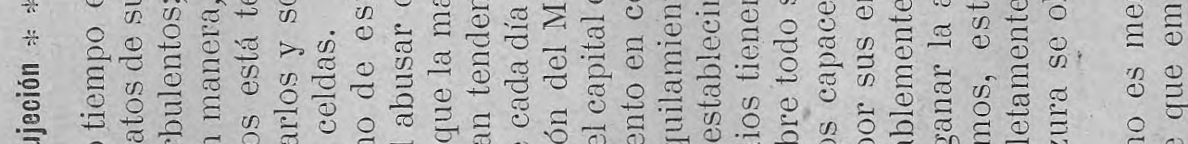

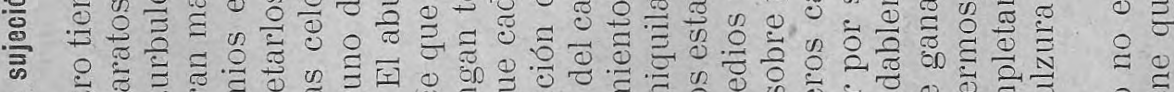
\%

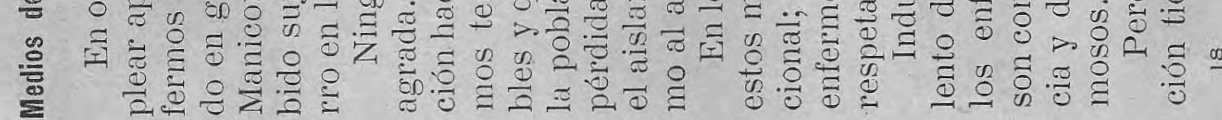



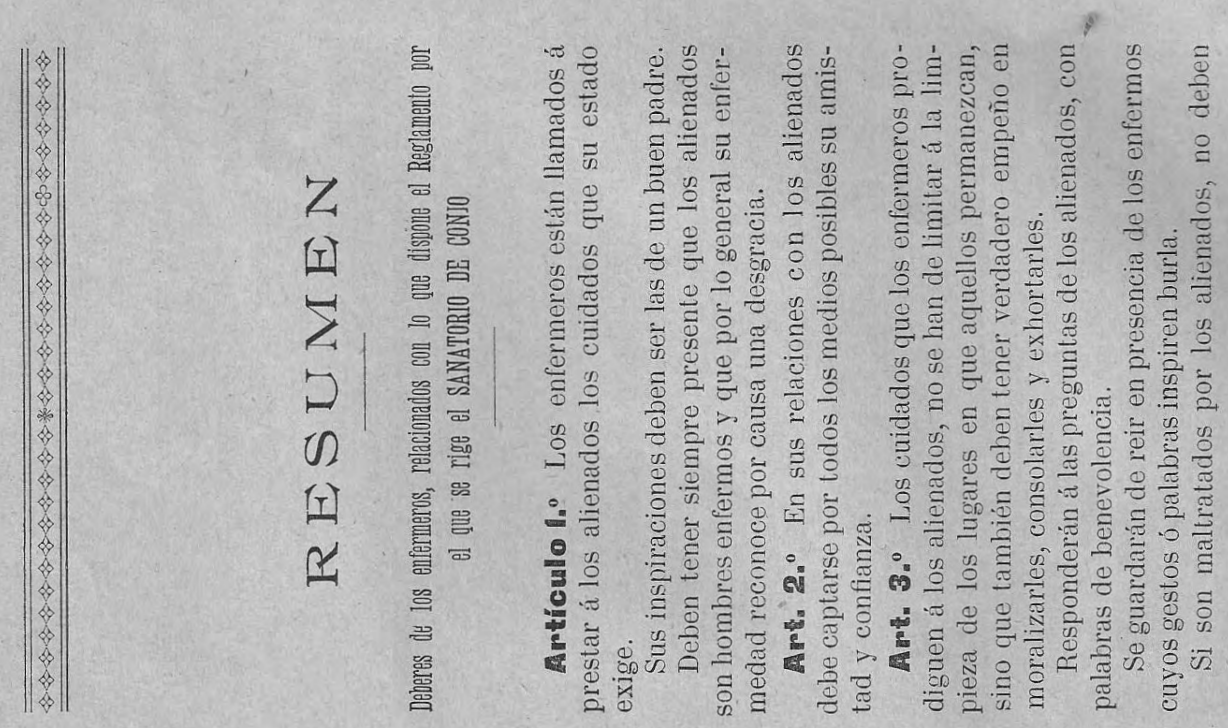


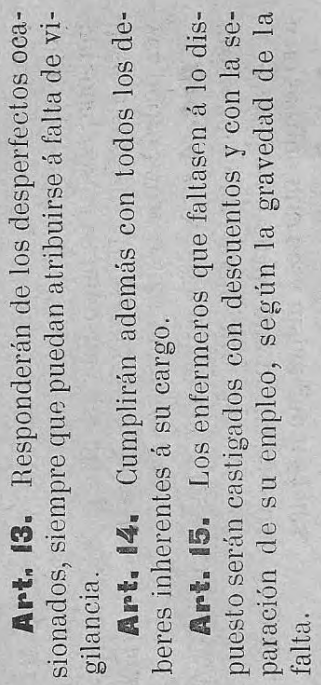

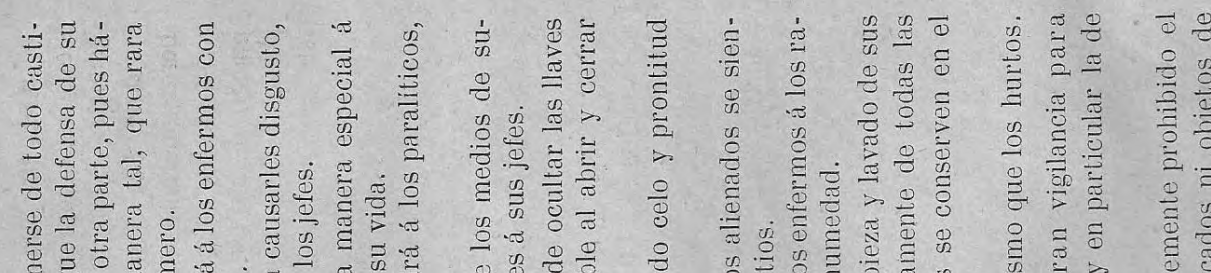

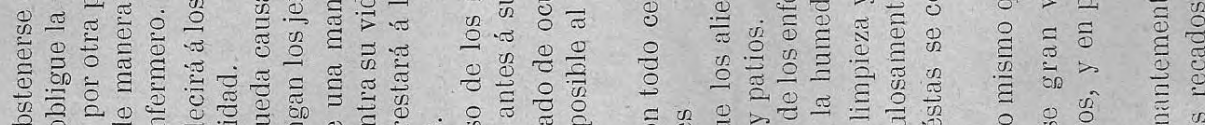

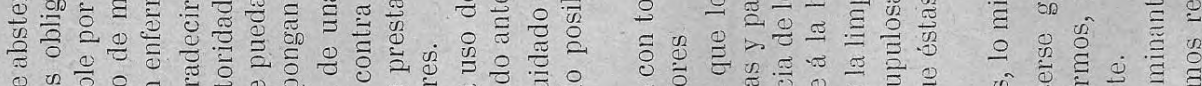

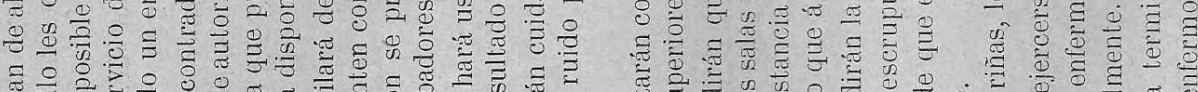

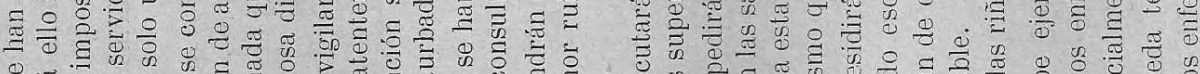

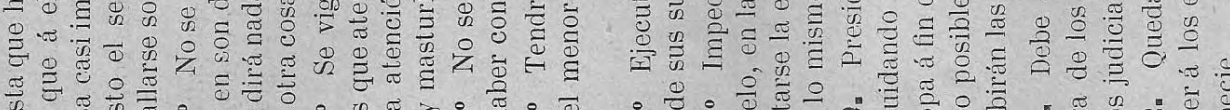

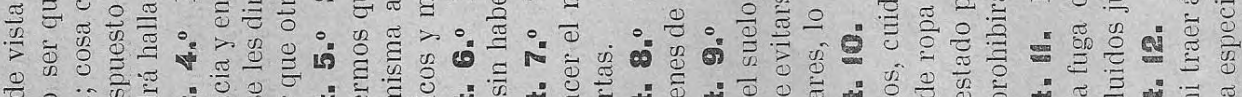

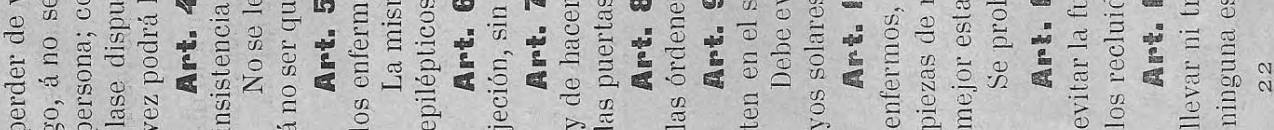

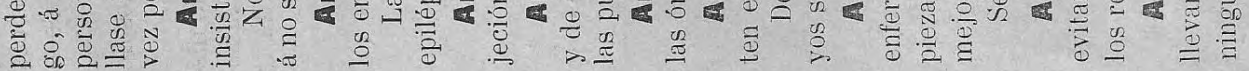

